\title{
Breast Complex Fibroadenoma
}

National Cancer Institute

\section{Source}

National Cancer Institute. Breast Complex Fibroadenoma. NCI Thesaurus. Code C5194.

A breast fibroadenoma that displays fibrocystic changes including apocrine metaplasia, sclerosing adenosis, and cyst formation. 